\title{
Modeling and evaluation of the energy saving under the improvements of the calibrators of temperature using by finite element method
}

\author{
Vladimir Skliarov ${ }^{1,3^{*}}$, Maxim Zalohin ${ }^{2}$, and Svetlana Fil $^{1}$ \\ ${ }^{1}$ National Scientific Centre „Institute of Metrology“, 42, Myronosytska str., 61002, Kharkiv, Ukraine \\ ${ }^{2}$ Kharkiv National Automobile and Highway University, 25, Yaroslava Mudrogo str., 610002, Kharkiv, Ukraine \\ ${ }^{3}$ O.M. Beketov National University of Urban Economy in Kharkiv, 17, Marshal Bazhanov str., 610002, Kharkiv, Ukraine
}

\begin{abstract}
Energy saving and rational use of energy resources is a priority direction for the development of the Ukrainian economy. Reduction of costs for production, performance of works and provision of services of specified quality is determined by the Law of Ukraine on energy saving [1]. The oil, gas and oil refining industry of Ukraine is one of the strategic sectors of the economy, which provides the needs of industrial enterprises, housing and motor transport complex. Metrological support of oil and gas wells for the assessment of their technical condition is carried out using the deep recording manometers. The pressure and temperature of the well are one of the main parameters that are used both to establish the working regime of the formation and the well, and to select the type and regime of the oilfield equipment.
\end{abstract}

\section{Introduction}

To automate the process of thermostating calibrated pressure gauges and to increase the accuracy of temperature control in the NSC "Institute of Metrology" calibrators of temperature with different temperature ranges have been developed. As a result of development, calibrators of temperature for calibration of pressure gauges for wells are manufactured and certified. The main parts of the calibrator are the thermostat and the control unit. The heating element of the thermostat is isolated from the environment by means of heatinsulating wool. Reproduction and maintenance of the set temperature is carried out by the control unit and the heating coil. The investigated temperature calibrator with the control unit is shown in Fig. 1.
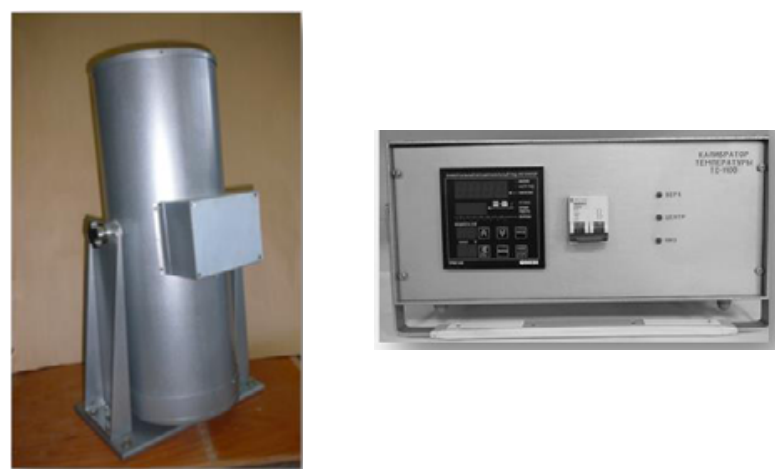

Fig. 1. Temperature Calibrator with Control Unit
Technical and metrological characteristics are presented in Table 1.

Table 1. Technical and metrological characteristics

\begin{tabular}{|l|c|}
\hline Repeatable temperature range, $\mathrm{K}$ & $\begin{array}{c}\text { from } 373 \\
\text { to } 1273\end{array}$ \\
\hline $\begin{array}{l}\text { Limits of the permissible basic error of } \\
\text { temperature reproduction over the range, } \mathrm{K}\end{array}$ & $\begin{array}{c}\text { from } \pm 273.5 \\
\text { to } \pm 274.2\end{array}$ \\
\hline Number of thermometric channels & 6 \\
\hline $\begin{array}{l}\text { Diameter of the channel in the leveling } \\
\text { block, mm }\end{array}$ & $12,8,6$ \\
\hline Channel depth in the leveling block, mm & 200 \\
\hline $\begin{array}{l}\text { The number of channels in the control unit } \\
\text { for measuring the calibrated measurement } \\
\text { equipment }\end{array}$ & 5 \\
\hline $\begin{array}{l}\text { Depth of immersion the calibrated } \\
\text { measurement equipment, mm }\end{array}$ & 400 \\
\hline
\end{tabular}

The purpose of this work is to improve the existing design of the temperature calibrator to determine the minimum time to enter into operation by applying an effective thermal screening of the volume of the temperature calibrator. Ensuring the stability of maintaining the specified temperature conditions of the calibrator without increasing the power consumption.

\section{Statement of the thermal problem}

Heat transfer processes occur in space and time. Therefore, the study of thermal conductivity reduces to the study of the space-time temperature change, i.e., to

\footnotetext{
*Corresponding author: vladimir.skliarov@metrology.kharkov.ua
} 
finding the dependence $T=f(x, y, z, t)$, where $(x, y, z)$ - the spatial coordinates in the Cartesian system - time. The set of temperature values at all points of the space under study is called a temperature field, $t$ time. To solve the problems associated with finding the temperature field, it is necessary to have a differential heat equation, which gives a relationship between temperature, time and the coordinates of the elementary volume. In the Cartesian coordinate system, for nonstationary thermal conductivity $\partial t / \partial \tau \neq 0$, the differential equation for isotropic materials and in the presence of internal heat sources is written in the form of a Poisson equation $[2,3]$ :

$$
\frac{\partial^{2} t}{\partial x^{2}}+\frac{\partial^{2} t}{\partial y^{2}}+\frac{\partial^{2} t}{\partial z^{2}}+\frac{q_{v}}{\lambda}=\frac{\partial t}{\partial \tau},
$$

where $\lambda$ - coefficient of thermal conductivity, $q_{v}=f(x, y, z, t)$ - distributed heat source in the body.

The mathematical formulation of the presented problem includes the differential heat equation, which describes the heat transfer within the body, the geometric shape, the initial and boundary conditions. The initial conditions consist in setting the law of temperature distribution at the initial instant of time $t_{0}$. To solve the problem, it was assumed that the initial temperature is evenly distributed throughout the volume of the calibrator and is $t_{0}=20^{\circ} \mathrm{C}$. The geometry of the temperature calibrator is shown in Fig. 2.

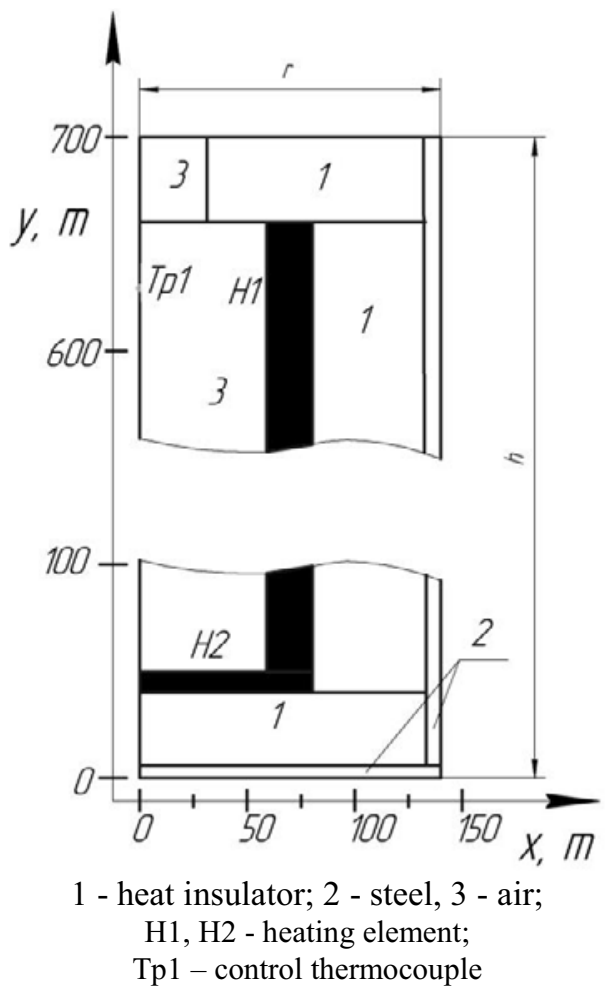

Fig. 2. Geometry of the temperature calibrator
In the presented form, the solution of the heat problem is a classical solution of a two-dimensional nonstationary problem with a boundary condition of the third kind. Boundary conditions determine the law of interaction between the environment and the surface of the body. The boundary condition of the third kind characterizes the law of heat exchange between the surface and the environment during cooling and heating. To describe the process of heat exchange between the body surface and the medium, the Newton-Richman law is used.

According to the Newton-Richman law, the amount of heat given by the unit of the surface of the body per unit time is proportional to the difference between the surface temperature of the body $t_{\text {surface }}$ (the surface of the wall of the temperature calibrator) and the environment $t_{\text {air }}$, and $t_{\text {surface }}>t_{\text {air }}$, then, according to [3]:

$$
-\left.\lambda\left(\frac{\partial t}{\partial x}\right)\right|_{x=r}=\alpha\left(t_{\text {surface }}-t_{\text {air }}\right),
$$

where $\alpha$ - is the heat transfer coefficient $W / \mathrm{m}^{2} \cdot K$.

On the upper and lower walls, the boundary condition has the form:

$$
-\left.\lambda\left(\frac{\partial t}{\partial y}\right)\right|_{\substack{y=0, y=h}}=\alpha\left(t_{\text {surface }}-t_{\text {air }}\right),
$$

Due to the symmetry of the geometric shape along the $\mathrm{Y}$ axis, the boundary condition has the form [3]:

$$
\left.\frac{\partial t}{\partial y}\right|_{x=0}=0
$$

According to the law of Joule-Lorentz, the intensity of volumetric thermal radiation in an electric heater when a current flows $I$ along it along the length $L$, taking into account the specific resistance of the nichrome thread, is described by the well-known expression [3]:

$$
\frac{q_{v}}{\lambda}=\frac{I^{2} \cdot R}{V},\left(W / m^{3}\right),
$$

where $R=\frac{\rho \cdot L}{S},(\Omega),\left(S=0,785 \cdot d_{H}^{2}\right.$ - the crosssectional area of the nichrome thread, $d_{H}$ - diameter of nichrome thread); $V=\frac{\pi \cdot\left(D^{2}-d^{2}\right)}{4} \cdot L$ - volume of nichrome spiral, $m^{3}$.

The greatest difficulty in the formation of the boundary condition (2) is the determination of the coefficient of heat transfer between the volume of the 
cylinder and the surrounding medium with the free movement of the fluid at a constant temperature $t_{\text {air }}=$ const . A concrete numerical value for this pair of interactions is not given in the literature. Also, it is not correct to take it $\alpha=$ const, since its value primarily depends on temperature. Therefore, to determine the function $\alpha=f\left(T_{\text {surface }}\right)$, it is proposed to use the criterion Nusselt formula given in the literature $[3,4]$ in the form:

$$
\overline{N u}_{f, h}=0,73 \cdot R a_{f}^{0,25} \cdot \varepsilon_{t},
$$

where $R a$ - Rayleigh number under laminar flow $\left(10^{3}<R a \leq 10^{9}\right), \quad \varepsilon_{t}=\left(\frac{\operatorname{Pr}_{t}}{\operatorname{Pr}_{w}}\right)^{0.25} \quad$ - environmental emission factor, $\operatorname{Pr}_{f}$ - Prandtl's criterion for $t_{\text {air }}=$ const, $\operatorname{Pr}_{w}$ - Prandtl's criterion for $t_{\text {air }}=$ var, the indices $\mathrm{f}, \mathrm{w}$ denote the fluid and the wall, respectively.

Taking into account that the heat exchange occurs with free convection between the air and the wall of the calibrator in a ventilated room, the emission factor can be taken to be equal to unity $\varepsilon_{t} \cong 1$, and the Rayleigh number $R a \cong 10^{9}$.

In turn, the dependence of the Nusselt number on the heat transfer coefficient $\alpha$ has the form [3, 4]:

$$
\overline{N u}_{f, h}=\frac{\alpha \cdot R_{0}}{\lambda}
$$

where $R_{0}=h \quad$ - calibrator height, $m$; $\lambda=f\left(T_{\text {surface }}\right)$ - coefficient of thermal conductivity of air in the border zone of the calibrator, when $t_{\text {air }} \cong t_{\text {surface }}$.

The specific heat output in the heater is controlled by the value of the current $I$ on the basis of the indication of the control thermocouple Tp1 by means of a PID controller. The mathematical description of the heat dissipation control process is performed using a transfer function in the MATLAB environment of the Simulink application (Fig. 3). The transfer function is represented by an aperiodic link of the first order in the form $k /\left(T_{S}+1\right)^{[5] . ~ T h e ~ c o e f f i c i e n t s ~} k=175$ and the time constant $T_{S}=2800$ are chosen as follows.

At the first stage of modeling the heat generation workflow, in the ANSYS program, a constant value of the current $I=25 \mathrm{~A}$ was assigned at the ends of the nichrome filament, corresponding to the maximum heat release power $W=3300 \mathrm{~W}$ for the entire time interval $t=10800 \mathrm{~s}$. Then, the numerical results of the heat generation simulation were imported into the MATLAB environment as an array of data, by which the function was determined $T=f(t)$ corresponding to the maximum possible heat release.

At the second stage of modeling for the function $T=f(t)$ the corresponding coefficients of the aperiodic link were chosen with an error of $1 \%$. In the third stage of the simulation, a heating element control system with a PID controller and a current limiter was built in the MATLAB environment using the Saturation unit, which automatically limits the current strength above 25 A (Fig. 3) [5]. At the entrance to the control system, a temperature threshold $T=1000^{\circ} \mathrm{C}$ was set, which was determined on the basis of the reading of the control thermocouple Tp1.

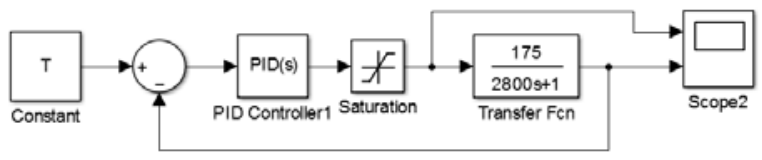

Fig. 3. Simulink-model of the calibrator heat dissipation working process

As a result of the control system simulation, a txt control file was generated as a function $I=f(T, t)$, which was imported into the ANSYS program. To achieve the goal, the PID regulator coefficients were selected in the manual tuning mode so that the maximum temperature of $1000^{\circ} \mathrm{C}$ was reached during the time $t=7200 \mathrm{~s}$, while the error of regulation did not exceed $5 \%$. For this purpose, four variants of manual adjustment modes with corresponding PID regulator coefficients (Table 2) were calculated by the calculated MATLAB program.

\begin{tabular}{|c|c|c|c|c|c|c|c|}
\hline & $P$ & I & D & $\mathrm{N}$ & $\begin{array}{c}\text { Rise } \\
\text { time, } s\end{array}$ & $\begin{array}{l}\text { Setting } \\
\text { time, } s\end{array}$ & $\begin{array}{c}\text { Power, } \\
k W^{*} h\end{array}$ \\
\hline 1 & $\begin{array}{l}\text { तु } \\
\text { है } \\
0\end{array}$ & $\begin{array}{l}\hat{0} \\
\dot{\gamma} \\
\dot{n}\end{array}$ & $\begin{array}{l}0 \\
i \\
1\end{array}$ & $\begin{array}{l}\text { I } \\
8 \\
0 \\
0\end{array}$ & $\underset{\nearrow}{\stackrel{\vartheta}{\ni}}$ & $\frac{0}{6}$ & $\stackrel{\imath}{-}$ \\
\hline 2 & $\begin{array}{l}\frac{1}{1} \\
0 \\
0\end{array}$ & $\begin{array}{l}0 \\
\dot{0} \\
\dot{\gamma} \\
\hat{\sigma}\end{array}$ & $\begin{array}{l}\vec{n} \\
\dot{0} \\
i\end{array}$ & 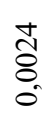 & 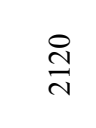 & ¿̊. & $\stackrel{\infty}{\circ}$ \\
\hline 3 & $\begin{array}{l}\infty \\
\stackrel{8}{8} \\
0\end{array}$ & 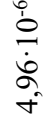 & $\stackrel{m}{\stackrel{m}{i}}$ & $\begin{array}{l}\infty \\
\stackrel{0}{0} \\
0\end{array}$ & ஓ̊̊ & ్ㅠ & $\begin{array}{l}\tilde{N} \\
\tilde{i}\end{array}$ \\
\hline 4 & $\underset{0}{\infty}$ & $\begin{array}{l}\dot{0} \\
\dot{\delta} \\
0\end{array}$ & ते & 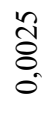 & $\stackrel{?}{=}$ & ๙ે & $\stackrel{\cong}{=}$ \\
\hline
\end{tabular}

Table 2. PID controller and heat dissipation parameters

The result of the calculation of the control system is shown in Fig. 4. 


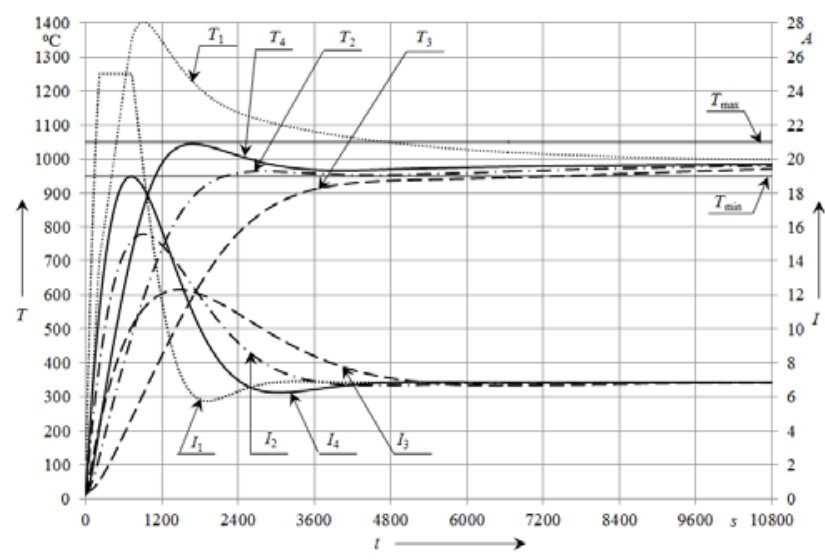

$I_{1}, I_{2}, I_{3}, I_{4}-$ the current dependence on time with the corresponding parameters of the PID controller;

$T_{1}, T_{2}, T_{3}, T_{4}$ - the temperature dependence on time with the corresponding parameters of the PID controller;

Tmin, Tmax - threshold values of the steady-state temperature.

Fig. 4. The results of the heat dissipation simulation with the corresponding parameters of the PID regulator (the index denotes the row parameter number in Table 2)

\section{Building and solving 3-D finite element model}

The classical heat conduction problem found a practical solution for determining the temperature distribution in the insulation wall. In this connection, using the ANSYS capabilities, an input file was created in the programming language APDL, the content of which reflects: geometry construction, finite element type specification and non-linear material properties, grid partitioning into finite elements, boundary conditions applications and adjustment of the solver options. The modeling problem was solved in a two-dimensional representation of the geometry of the temperature calibrator.

To reduce the amount of computing resources and increase the speed of solving the problem, the geometry of the temperature calibrator is made in the $\mathrm{X}-\mathrm{Y}$ plane. In this case, the $Y$ axis is the axis of symmetry. To create a finite-element model, a 4-node flat axis symmetric element with two-dimensional thermal conductivity and one degree of freedom was used - PLANE 55.

PLANE55 can be used as a plane element or as an axisymmetric ring element with a two-dimensional thermal conduction capability. The element has four nodes with a single degree of freedom, temperature, at each node.) The element is applicable to a twodimensional, steady-state or transient thermal analysis. The element can also compensate for mass transport heat flow from a constant velocity field. [6,7].

Using the above-described final element, the grid is automatically constructed with a given size of a finite element of $1 \mathrm{~mm}$ (see Fig. 5). For better convergence of the solution of the problem, the net of finite elements is thickened. Taking into account the axisymmetric of the model, for clarity, the temperature calibrator is shown in Fig. 5. As a result of the construction of the grid, 13734 finite elements and 15360 nodes were created.

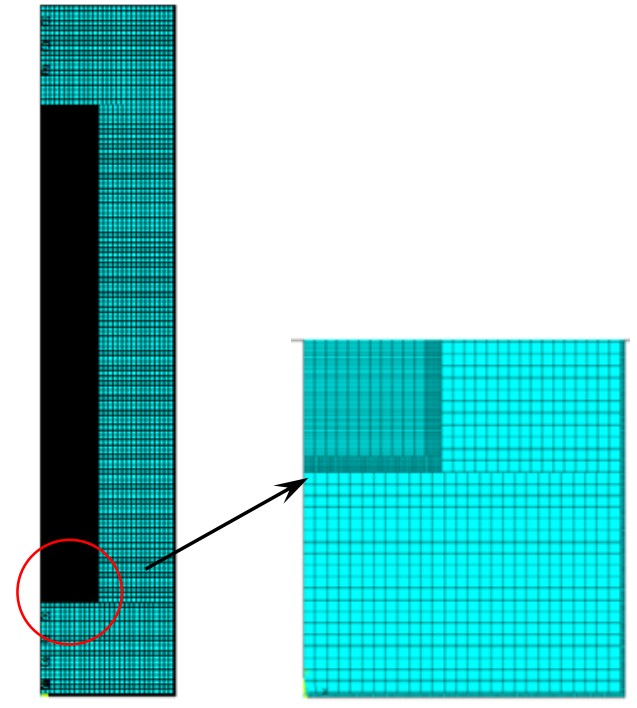

Fig. 5. The calibrator's FE model

As the thermal insulation, mullite is used for the siliceous fibrous material MKRP-340 (GOST 23619-79) [8].

When modeling the temperature field of the temperature calibrator, the temperature dependence of the material properties in the temperature range from 293 $\mathrm{K}$ to $1373 \mathrm{~K}$ was taken into account. Thermophysical properties of the temperature calibrator materials are presented

in Table 3 [9-12].

Table 3. Thermophysical properties

\begin{tabular}{|l|c|c|c|}
\hline Material & $\begin{array}{c}\text { Density of the } \\
\text { material, } \rho, \\
\mathrm{kg} / \mathrm{m}^{3}\end{array}$ & $\begin{array}{c}\text { Thermal } \\
\text { conductivity, } \lambda, \\
\mathrm{W} / \mathrm{m} \cdot \mathrm{K}\end{array}$ & $\begin{array}{c}\text { Specific } \\
\text { heat, } \mathrm{c}, \\
\mathrm{J} / \mathrm{kg} \cdot \mathrm{K}\end{array}$ \\
\hline Air & $1.205-0.277$ & $0.0257-0.0807$ & $1005-1185$ \\
\hline $\begin{array}{l}\text { Heating } \\
\text { element }\end{array}$ & $8500-8189$ & $17.4-24.7$ & $450-508$ \\
\hline Insulator & $180-242$ & $0,09-0,62$ & $800-1063$ \\
\hline $\begin{array}{l}\text { Outer } \\
\text { casing }\end{array}$ & $7850-7548$ & $86-30$ & $444-650$ \\
\hline
\end{tabular}

\section{The results and analysis of the modeling}

As a result of the simulated heat dissipation in the calibrator (Table 2), the following conclusions can be drawn:

- the time to reach the steady state can be reduced from 2 hours to 40 minutes by appropriately setting the parameters of the heater control system;

- the power that is consumed at the temperature output in the steady-state mode of $1000^{\circ} \mathrm{C}$ has almost halved; - the simulation error does not exceed 5\%.

In addition, the temperature dependences of the calibrator shell heating are obtained when placed inside different types of temperature sensors. Calculations using real operating temperatures with various convection coefficients on the surface of the calibrator case were carried out. An estimation of the calculation 
results for various types of finite elements of the 2D model of the temperature calibrator is carried out.

When specifying a finite element grid, both the finite element size selection mode and the Smart size mode were used. Modeling of operating modes was carried out in the educational version of the ANSYS software package using the APDL programming language.

Based on the proposed models of geometry, an analysis and calculation of the energy-saving shell for different number of simultaneously calibrated temperature sensors has been carried out.

\section{Conclusions}

On the basis of the performed modeling the constructive solution of the temperature calibrator is proposed to reduce (from 2 hours to 50 minutes) the time of reaching the operating mode of uniform thermal stabilization. The methodology of ensuring the stability of maintaining the set temperature conditions of the calibrator without increasing the power consumption is determined. The requirements for the power source of the heating element and its location are formulated.

As perspective directions of further work, it is possible to determine the design and experimental studies of the new design of the temperature calibrator using an additional low-power heating element. The proposed methodology for modeling temperature regimes is applicable in the study and study of the temperature regimes of national standards in the field of thermometry and calibration of deep recording gauges.

As a practical application, the proposed simulation and calculation algorithm is used to reduce the systematic error of national measurement standards in the field of thermometry during international comparisons of COOMET programs.

The authors are grateful to Prof. Dr. Pavel Neyezhmakov for his valuable discussion and suggestions concerning the results of modeling and evaluation of the energy saving under the improvements of the calibrators of temperature using by finite element method. The problems of adaptation and application of these results for international comparisons on the COOMET Projects were discussed. This inspired us to do research of the modeling and evaluation of the new design of calibrator of temperature. Special thanks to - Dr. Mikola Huriev and Dipl. eng. Andrew Zabelskyi for assistance in the installation of an academic version of the FEM software.

\section{References}

1. The Law of Ukraine On Energy Saving, www. zakon.rada.gov.ua/laws/show/74/94-вp.

2. A.V. Lykov Theory of heat conductivity. - Moscow: Higher School, 1967. - 598 p.

3. V.P. Isachenko Heat transfer / Isachenko V.P., Osipova V.A., Sukomel A.S.. -M.: Energoizdat, 1981. -416 p.

4. Webpage:

http://www.ispu.ru/files/u2/SP._bez_nomera_-
Raschet_koefficienta_konvektivnoy_teplootdachi_ osnov._kriter._uravneniya.pdf

5. Webpage: http://www.cta.ru/cms/f/342946.pdf

6. Webpage: http://www.cadfem.ru

7. Webpage:

http://www.ansys.com/products/academic/ansysstudent

8. Refractory heat-insulating Mullite-silica glassfibrous materials and products. Specifications. (GOST 23619-79)

9. Thermophysical properties of substances, Handbook. Ed. N.B. Vargaftika. Leningrad: State Energy Publishing House. 1956 - 367 p.

10. Thermophysical properties of materials, Handbook. Ed. V.S. Chirkin. Moscow: State Publishing of physical-technical literatures. 1959 - 357 p.

11. Webpage: http://thermalinfo.ru

12. Webpage:

http://www.lib.tpu.ru/fulltext/c/2009/C01/V2/160.pdf 